\title{
Probabilistic multi-item inventory model with varying mixture shortage cost under restrictions
}

\author{
Hala A. Fergany ${ }^{*}$
}

\author{
*Correspondence: \\ halafergany@yahoo.com \\ Department of Mathematics, \\ Faculty of Science, Tanta \\ University, Tanta, Egypt
}

\begin{abstract}
This paper proposed a new general probabilistic multi-item, single-source inventory model with varying mixture shortage cost under two restrictions. One of them is on the expected varying backorder cost and the other is on the expected varying lost sales cost. This model is formulated to analyze how the firm can deduce the optimal order quantity and the optimal reorder point for each item to reach the main goal of minimizing the expected total cost. The demand is a random variable and the lead time is a constant. The demand during the lead time is a random variable that follows any continuous distribution, for example; the normal distribution, the exponential distribution and the Chi square distribution. An application with real data is analyzed and the goal of minimization the expected total cost is achieved. Two special cases are deduced.
\end{abstract}

Keywords: Probabilistic inventory model, Multi-item, Varying mixture shortage, Stochastic lead time demand

\section{Backround}

The multi-item, single source inventory system is the most general procurement system which may be described as follows; an inventory of n-items is maintained to meet the average demand rates designated $\bar{D}_{1}, \bar{D}_{2}, \bar{D}_{3}, \ldots \ldots \bar{D}_{n}$. The objective is to decide when to procure each item, how much of each item to procure, in the light of system and cost parameters.

Hadley and Whiten (1963) treated the unconstrained probabilistic inventory models with constant unit of costs. Fabrycky and Banks (1965) studied the multi-item multi source concept and the probabilistic single-item, single source (SISS) inventory system with zero lead-time, using the classical optimization. Abou-El-Ata and Kotb (1996), Abou-El-Ata et al. 2003) studied multi-item EOQ inventory models-with varying costs under two restrictions. Moreover, Fergany and El-Saadani (2005, 2006; Fergany et al. 2014) treated constrained probabilistic inventory models with continuous distributions and varying costs.

The two basic questions that any continuous review $\langle\mathrm{Q}, \mathrm{r}\rangle$ inventory control system has to answer are; when and how much to order. Over the years, hundreds of papers and books have been published presenting models for doing this under a wide variety of

(c) 2016 The Author(s). This article is distributed under the terms of the Creative Commons Attribution 4.0 International License (http://creativecommons.org/licenses/by/4.0/), which permits unrestricted use, distribution, and reproduction in any medium, provided you give appropriate credit to the original author(s) and the source, provide a link to the Creative Commons license, and indicate if changes were made. 
conditions and assumptions. Most authors have shown that the demand that cannot be filled from stock then backordered or the lost sales model are used. Several $\langle\mathrm{Q}, \mathrm{r}\rangle$ inventory models with mixture of backorders and lost were proposed by Ouyang et al. (1996), Montgomery et al. (1973) and Park (1982). Also, Zipkin (2000) shows that demands occurring during a stockout period are lost sales rather than backorders.

In this paper, we investigate a new probabilistic multi-item single-source (MISS) inventory model with varying mixture shortage cost (backorder and lost sales) as shown in Fig. 1 under two restrictions. One of them is on the expected varying backorder cost and the other one the expected varying lost sales cost. The optimal order quantity $Q_{i}^{*}$, the optimal reorder point $r_{i}^{*}$ and the minimum expected total cost [min E (TC)] are obtained. Moreover, two special cases are deduced and an application with real data is analyzed.

\section{The following notations are adopted for developing the model}

$\langle Q, r\rangle=$ the continuous review inventory system

MISS $=$ The Multi-item single-source,

$D_{i}=$ The demand rate of the $i$ th item per period,

$\bar{D}_{i}=$ The expected demand rate of the $i$ th item per period,

$Q_{i}=$ The order quantity of the $i$ th item per period,

$Q_{i}^{*}=$ The optimal order quantity of the $i$ th item per period,

$r_{i}=$ The reorder point of the $i$ th item per period,

$r_{i}^{*}=$ The optimal reorder point of the $i$ th item per period,

$\bar{n}_{i}=$ The expected number order of the $i$ th item per period,

$L_{i}=$ The lead-time between the placement of an order and its receipt of the $i$ th item,

$\bar{L}_{i}=$ The average value of the lead time $L_{i}$,

$x_{i}=$ The random variables represent the lead time demand of the $i$ th item per period,

$f\left(x_{i}\right)=$ The probability density function of the lead time demands,

$E\left(x_{i}\right)=$ The expected value of $x_{i}$,

$r_{i}-x_{i}=$ The random variable represents the net inventory when the procurement quantity arrives if the lead-time demand $\mathrm{x} \leq \mathrm{r}$,

$\bar{H}_{i}=$ The average on hand inventory of the $i$ th item per period

$R(r)=p\left(x_{i}>r\right)=$ The probability of shortage $=$ the reliability function,

$\bar{S}\left(r_{i}\right)=$ The expected shortage quantity per period

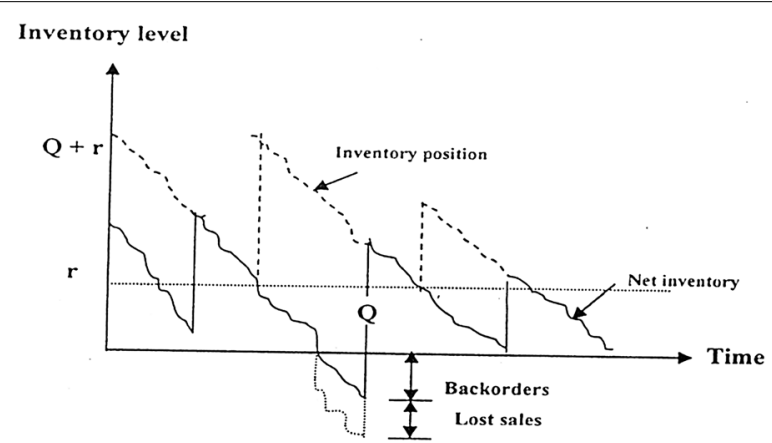

Fig. 1 The inventory model 
$c_{o i}=$ The order cost per unit of the $i$ th item per period,

$c_{h i}=$ The holding cost per unit of the $i$ th item per period,

$c_{s i}=$ The shortage cost per unit of the $i$ th item per period,

$c_{b i}=$ The backorder cost per unit of the $i$ th item per period,

$c_{l i}=$ The lost sales cost per unit of the $i$ th item per period,

$c_{s i}(n)=$ The varying shortage cost of the $i$ th item per period,

$\Phi_{D}(t)=$ The characteristic function of demand,

$\Phi_{x}(t)=$ The characteristic function of lead time demand $\mathrm{x}$,

$\beta=$ A constant real number selected to provide the best fit of estimated expected

cost function,

$\gamma_{i}=$ The backorder fraction of the $i$ th item, $0<\gamma_{i}<1$,

$E(O C)=$ The expected order (procurement) cost per period,

$E(H C)=$ The expected holding (carrying) cost per period,

$E(S C)=$ The expected shortage cost per period,

$E(B C)=$ The expected backorder cost per period,

$E(L C)=$ The expected lost sales cost per period,

$E(T C)=$ The expected total cost function,

Min $E(T C)=$ The minimum expected total cost function.

$K_{b i}=$ The limitation on the expected annual varying backorder cost for backorder model of the $i$ th item,

$K_{l i}=$ The limitation on the expected annual varying lost sales cost for lost sales model of the $i$ th item.

\section{Mathematical model}

We will study the proposed model with varying mixture shortage cost constraint when the demand $\mathrm{D}$ is a continuous random variable, the lead-time $\mathrm{L}$ is constant and the distribution of the lead time demand (demand during the lead time) is known.

It is possible to develop the expected annual total cost as follows:

$$
\mathrm{E}(\text { Total Cost })=\sum_{i=1}^{m}[E(\text { Order Cost })+E(\text { Holding Cost })+E(\text { Shortage Cost })]
$$

i.e.

$$
E[T C(Q, r)]=\sum_{i=1}^{m}\left[\begin{array}{l}
\left(c_{o i}\left(\frac{\bar{D}_{i}}{Q_{i}}\right)\right)+c_{h i}\left(\frac{Q_{i}}{2}+r_{i}-E\left(x_{i}\right)\right)+c_{b i} \gamma\left(\frac{\bar{D}_{i}}{Q_{i}}\right)^{\beta+1} \int_{r}^{\infty}\left(x_{i}-r_{i}\right) f\left(x_{i}\right) d x_{i} \\
+\left(c_{l i}\left(\frac{\bar{D}_{i}}{Q_{i}}\right)^{\beta+1}+c_{h i}\right)\left(1-\gamma_{i}\right) \int_{r}^{\infty}\left(x_{i}-r_{i}\right) f\left(x_{i}\right) d x_{i}
\end{array}\right]
$$

where; $\int_{r}^{\infty}\left(x_{i}-r_{i}\right) f\left(x_{i}\right) d x_{i}=\bar{S}\left(r_{i}\right)$

The objective is to minimize the expected annual total cost $\mathrm{E}[\mathrm{TC}(\mathrm{Q}, \mathrm{r})]$ under two constraints:

$$
c_{b i} \gamma_{i}\left(\frac{\bar{D}_{i}}{Q_{i}}\right)^{\beta+1} \bar{S}\left(r_{i}\right)-K_{b i} \leq 0
$$




$$
c_{l i}\left(1-\gamma_{i}\right)\left(\frac{\bar{D}_{i}}{Q_{i}}\right)^{\beta+1} \bar{S}\left(r_{i}\right)-K_{l i} \leq 0
$$

To solve this primal function which is a convex programming problem, let us write the previews equations in the following form:

$$
E[T C(Q, r)]=\sum_{i=1}^{m}\left[\begin{array}{l}
\left(c_{o i} \frac{\bar{D}_{i}}{Q_{i}}\right)+c_{h i}\left(\frac{Q_{i}}{2}+r_{i}-E\left(x_{i}\right)\right) \\
+\left(c_{b i} \gamma\left(\frac{\bar{D}_{i}}{Q_{i}}\right)^{\beta+1} \bar{S}\left(r_{i}\right)\right)+\left(c_{l i}\left(\frac{\bar{D}_{i}}{Q_{i}}\right)^{\beta+1}+c_{h i}\right)\left(1-\gamma_{i}\right) \bar{S}\left(r_{i}\right)
\end{array}\right]
$$

Subject to:

$$
\left.\begin{array}{r}
c_{b i} \gamma_{i}\left(\frac{\bar{D}_{i}}{Q_{i}}\right)^{\beta+1} \bar{S}\left(r_{i}\right)-K_{b i} \leq 0 \\
c_{l i}\left(1-\gamma_{i}\right)\left(\frac{\bar{D}_{i}}{Q_{i}}\right)^{\beta+1} \bar{S}\left(r_{i}\right)-K_{l i} \leq 0
\end{array}\right\}
$$

To find the optimal values $Q^{*}$ and $r^{*}$ which minimize Eq. (1) under the constraints (2), the Lagrange multiplier technique is used as follows:

$$
\begin{aligned}
L\left(Q_{i}, r_{i}, \lambda_{i 1} \lambda_{i 2}\right)= & \sum_{i=1}^{m}\left[\frac{\bar{D}_{i}}{Q_{i}}+c_{h i}\left\{\frac{Q_{i}}{2}+r_{i}-E\left(x_{i}\right)\right\}+c_{b i} \gamma_{i}\left(\frac{\bar{D}_{i}}{Q_{i}}\right)^{\beta+1} \bar{S}\left(r_{i}\right)\right. \\
& +\left\{c_{l i}\left(\frac{\bar{D}_{i}}{Q_{i}}\right)^{\beta+1}+c_{h i}\right\}\left(1-\gamma_{i}\right) \bar{S}\left(r_{i}\right)+\lambda_{1 i}\left\{c_{b i} \gamma_{i}\left(\left(\frac{\bar{D}_{i}}{Q_{i}}\right)^{\beta+1}\right) \bar{S}\left(r_{i}\right)-k_{b i}\right\} \\
& \left.+\lambda_{2 i}\left\{C_{l i}\left(1-\gamma_{i}\right)\left(\frac{\bar{D}_{i}}{Q_{i}}\right)^{\beta+1} \bar{S}\left(r_{i}\right)-k_{l i}\right\}\right],
\end{aligned}
$$

where $\lambda_{1 i}, \lambda_{2 i}$ are the Lagrange multipliers.

The optimal values $Q_{i}$ and $r_{i}$ can be calculated by setting each of the corresponding first partial derivatives of Eq. (3) equal to zero.

i.e.

$$
\frac{\partial L}{\partial Q_{i}}=0 \quad \frac{\partial L}{\partial r_{i}}=0
$$

then we obtain:

$$
\begin{aligned}
& C_{b i} Q_{i}^{* \beta+2}-2 C_{o i} Q_{i}^{* \beta}-2 A(\beta+1) \bar{S}\left(r_{i}\right)=0, \\
& R\left(r_{i}^{*}\right)=\left[\frac{C_{h i} Q_{i}^{* B+1}}{A+C_{h i}\left(1-\gamma_{i}\right) Q_{i}^{* \beta+1}}\right]
\end{aligned}
$$


where $A=\bar{D}_{i}^{\beta+1}\left[\gamma_{i} C_{h i}\left(1+\lambda_{1 i}\right)+\left(1-\gamma_{i}\right) C_{l i}\left(1+\lambda_{2 i}\right)\right]$

Clearly, there is no closed form solution of Eqs. (4), (5).

\section{Mathematical derivation of the lead time demand}

The lead time demand $X$ is the total demand $\mathrm{D}$ which accrue during the lead time $\mathrm{L}$. Consider that the lead time is a constant number of periods and demand is random variable.

Then,

$$
X=\sum_{i=1}^{L} D_{i}, \quad i=1,2, \ldots \ldots, L
$$

To determine the distribution of the lead time demand X: consider the characteristic function of $X$ and D are related as:

$$
\Phi_{x}(t)=\prod_{i=1}^{L} \Phi_{D}(t)=\left[\Phi_{D}(t)\right]^{L}
$$

We can deduce the corresponding distribution of the lead time demand $\mathrm{X}$ when the demand follows many continuous distributions. Consider $\mathrm{X}$ follows the normal distribution, the exponential distribution and the Chi square distribution.

\section{The demand follows the normal distribution}

If the demand $\mathrm{D}$ have the normal distribution with parameters $\mu, \sigma$,

$$
f(D)=\frac{1}{\sigma \sqrt{2 \pi}} e^{-\frac{1}{2}\left[\frac{D-\mu}{\sigma}\right]^{2}}, \quad-\infty<D<\infty,-\infty<\mu<\infty, \sigma>0
$$

Then the lead time demand follows the normal distribution with parameters $\mu L, L \sigma^{2}$

$$
f(x)=\frac{1}{\sigma \sqrt{2 \pi L}} e^{-\frac{1}{2 L}\left[\frac{x-\mu L}{\sigma}\right]^{2}}, \quad-\infty<x<\infty,-\infty<\mu L<\infty, \sigma L>0
$$

Also: $R(r)=\int_{r}^{\infty} f(x) d(x)$ i.e.

$$
R(r)=1-\phi\left(\frac{r-\mu L}{\sigma \sqrt{L}}\right)=\varphi\left[\frac{r-\mu L}{\sigma \sqrt{L}}\right]
$$

and

$$
\bar{S}(r)=\sigma \sqrt{L} \Psi\left(\frac{r-\mu L}{\sigma \sqrt{L}}\right)+(\mu L-r) \varphi\left(\frac{r-\mu L}{\sigma \sqrt{L}}\right)
$$

where

$$
\Psi\left(\frac{r-\mu L}{\sigma \sqrt{L}}\right)=\frac{1}{\sqrt{2 \pi}} \int_{\frac{r-\mu L}{\sigma \sqrt{L}}}^{\infty} y e^{-\frac{1}{2} y^{2}} d y
$$


Hence, the expected annual total cost can be minimized mathematically by substituting from Eq. (6) into (4), (5) we get (7), (8)

$$
C_{h i} Q_{i}^{* \beta+2}-2 C_{o i} Q_{r}^{* \beta}-2 A(\beta+1)\left[\sigma \sqrt{L} \Psi\left(\frac{r-\mu L}{\sigma \sqrt{L}}\right)+(\mu L-r) \varphi\left(\frac{r-\mu L}{\sigma \sqrt{L}}\right)\right],
$$

and

$$
\phi\left(\frac{r-\mu L}{\sigma \sqrt{L}}\right)=\left[\frac{C_{h i} Q_{i}^{* \beta+1}}{C_{h i}(1-\gamma) Q_{i}^{* \beta+1}+A}\right]
$$

\section{The demand follows the exponential distribution}

If the demand $\mathrm{D}$ have the exponential distribution with parameter $\alpha$,

$$
f(x)=\alpha e^{-\alpha D}, \quad 0<D<\infty, \alpha>0
$$

Then, lead time demand follows the Gamma distribution with parameters $L, \alpha$

$$
\begin{gathered}
f(x)=\frac{\alpha^{L}}{\Gamma(L)} x^{L-1} e^{-\alpha x}, \quad 0<x<\infty, L>0, \alpha>0 \\
\text { also } R(r)=\frac{\alpha^{L}}{\Gamma(L)} \int_{r}^{\infty} x^{L-1} e^{-\alpha x} d x \text { then, } R(r)=\sum_{i=0}^{L-1}\left[\frac{(\alpha r)^{i} e^{-\alpha r}}{i !}\right] \\
\bar{S}(r)=\int_{r}^{\infty}(x-r) f(x) d x=\frac{\alpha^{L}}{\Gamma(L)} \int_{r}^{\infty}(x-r) x^{L-1} e^{-\alpha r} d x=\frac{\alpha^{L}}{\Gamma(L)} \int_{r}^{\infty} x^{L} e^{-\alpha r} d x-r R(r) \\
\bar{S}(r)=\frac{L}{\alpha}\left[\sum_{i=0}^{L}\left\{\frac{(\alpha r)^{i} e^{-\alpha r}}{i !}\right\}\right]-r\left[\sum_{i=0}^{L-1}\left\{\frac{(\alpha r)^{i} e^{-\alpha r}}{i !}\right\}\right]
\end{gathered}
$$

Hence, the expected annual total cost can be minimized mathematically by substituting from Eq. (9) into (4), (5) we get (10), (11)

$C_{h i} Q_{i}^{* \beta+2}-2 C_{o i} Q_{i}^{* \beta}-2 A(\beta+1)\left[\frac{L}{\alpha} \sum_{i=0}^{L}\left\{\frac{(\alpha r)^{i} e^{-\alpha r}}{i !}\right\}-r \sum_{i=0}^{L-1}\left\{\frac{(\alpha r)^{i} e^{-\alpha r}}{i !}\right\}\right]$,

and

$$
\varphi\left(\frac{r-\mu L}{\sigma \sqrt{L}}\right)=\left[\frac{C_{h i} Q_{i}^{* \beta+1}}{C_{h i}(1-\gamma) Q_{i}^{* \beta+1}+A}\right]=\sum_{i=0}^{L-1}\left[\frac{(\alpha r)^{i} e^{-\alpha r}}{i !}\right]
$$

\section{The demand follows the Chi square distribution}

If the demand $\mathrm{D}$ follows Chi-squire distribution with parameter $\frac{\eta}{2}$

$$
f(D)=\frac{1}{2^{\frac{\eta}{2}} \Gamma\left(\frac{\eta}{2}\right)} D^{\frac{\eta}{2}-1}, \quad 0<D<\infty, \frac{\eta}{2}>0
$$


Then lead time demand $\mathrm{X}$ follows the Chi-squire distribution with parameters $\frac{L \eta}{2}$

$$
f(x)=\frac{1}{2^{\frac{L \eta}{2}} \Gamma\left(\frac{L \eta}{2}\right)} x^{\frac{L \eta}{2}-1} \quad 0<x<\infty, \frac{L \eta}{2}>0,
$$

also

$$
R(r)=\sum_{i=0}^{\frac{L \eta}{2}-1}\left[\frac{\left(\frac{r}{2}\right)^{i} e^{-\frac{r}{2}}}{i !}\right]
$$

and

$$
\bar{S}(r)=L \eta\left[\sum_{i=0}^{\frac{L \eta}{2}}\left\{\frac{\left(\frac{r}{2}\right)^{i} e^{-\frac{r}{2}}}{i !}\right\}\right]-r\left[\sum_{i=0}^{\frac{L \eta}{2}-1}\left\{\frac{\left(\frac{r}{2}\right)^{i} e^{-\frac{r}{2}}}{i !}\right\}\right]
$$

Hence, the expected annual total cost can be minimized mathematically by substituting from Eq. (12) into (4), (5) we get (13), (14):

$C_{h i} Q_{i}^{* \beta+2}-2 C_{o i} Q_{i}^{* \beta}-2 A(\beta+1)\left[L \eta \sum_{i=0}^{\frac{L \eta}{2}}\left\{\frac{\left(\frac{r}{2}\right)^{i} e^{-\frac{r}{2}}}{i !}\right\}-r \sum_{i=0}^{\frac{L \eta}{2}}\left\{\frac{\left(\frac{r}{2}\right)^{i} e^{-\frac{r}{2}}}{i !}\right\}\right]$,

and

$$
\varphi\left(\frac{r-\mu L}{\sigma \sqrt{L}}\right)=\left[\frac{C_{h i} Q_{i}^{* \beta+1}}{C_{h i}(1-\gamma) Q_{i}^{* \beta+1}+A}\right]=\sum_{i=0}^{\frac{L \eta}{2}-1}\left[\frac{\left(\frac{r}{2}\right)^{i} e^{-\frac{r}{2}}}{i !}\right]
$$

\section{Special cases}

Two special cases of the proposed model are deduced as follows;

Case 1 Let $\gamma_{i}=0, \beta=0$ and $K_{b i} \rightarrow \infty \Rightarrow c_{s}(\bar{n})^{\beta}=c_{s}$ and $\lambda_{i}=0$. Thus Eqs. (4) and (5) become:

$$
Q^{*}=\sqrt{\frac{2 \bar{D}\left(c_{o}+c_{l} \bar{S}(r)\right)}{c_{h}}} \text { and } R\left(r^{*}\right)=\frac{c_{h} Q^{*}}{c_{h} Q^{*}+c_{l} \bar{D}}
$$

This is the unconstrained lost sales continuous review inventory model with constant units of cost, which are the same results as in Hadley and Whiten (1963). 
Case 2 Let $\gamma_{i}=1 \beta=0$ and $K_{l i} \rightarrow \infty \Rightarrow c_{s}(\bar{n})^{\beta}=c_{s}$ and $\lambda_{i}=0$.

Thus Eqs. (4) and (5) become:

$$
Q^{*}=\sqrt{\frac{2 \bar{D}\left(c_{o}+c_{b} \bar{S}(r)\right)}{c_{h}}} \text { and } R\left(r^{*}\right)=\frac{c_{h}}{c_{b} \bar{D}} Q \text {, }
$$

This is the unconstrained backorders continuous review inventory model with constant unit costs, which coincide with the result of Hadley and Whiten (1963).

\section{Applications}

A company for ready clothes produces three Items [Trousers: I, Shirt: II, and Jacket: III] of seasonal products (production takes two cycles and each cycle lasts for 6 months). Table 5 in Appendix shows the order quantity and the demand rate during the interval 2004-2008. But for some un expected reasons in some cycles, the company faces shortage and it has to pay penalty at least $1 \%$ for month for backorder and $3 \%$ for lost sale. Table 1 shows the maximum cost allowed for backorder $K_{b}$, lost sales $K_{L}$ and their fractions. Hence, the company wishes to put an optimal policy for production to minimize the expected total cost.

\section{Solution}

By using SPSS program, One-Sample Kolmogorov-Smirnov Test, the demand for the three Items is fitted to normal distribution, where Table 2 shows the K-S statistic with their $P$ values. Table 3 shows the average units cost for each item 2004-2008

The optimal values $Q^{*}$ and $r^{*}$ for three items can be found by using (7) and (8) respectively. The iterative procedure will be used to solve the equations.

Use the following numerical procedure:

*Step 1: Assume that $\bar{S}=0$ and $r=E(x)$, then from Eq. (7) we have: $Q_{0}=\sqrt{\frac{2 c_{0 i} \bar{D}_{i}}{c_{h i}}}$

* Step 2: Substituting $Q_{o}$ into Eq. (8) we obtain $r_{0}$

* Step 3: Substituting by $r_{0}$ from step 2 into Eq. (7) we can deduce $Q_{1}$

Table 1 The Maximum cost allowed (the limitations) for both backorder, lost sales and their fractions

\begin{tabular}{lllll}
\hline Items & \multicolumn{1}{l}{ Costs } & \multicolumn{1}{c}{} \\
\cline { 2 - 5 } & $\mathbf{K}_{\mathbf{b}}$ & $\mathbf{K}_{\mathbf{L}}$ & $\boldsymbol{\gamma}$ & $(\mathbf{1 - \gamma})$ \\
\hline Item (I) & 1680 & 13,720 & 0.56 & 0.44 \\
Item (II) & 1800 & 9300 & 0.70 & 0.30 \\
Item (III) & 1052 & 10,820 & 0.67 & 0.33 \\
\hline
\end{tabular}


Table 2 One-sample Kolmogorov-Smirnov test of the demands

\begin{tabular}{llll}
\hline & D1 & D2 & D3 \\
\hline $\mathrm{N}$ & 48 & 48 & 48 \\
$\begin{array}{l}\text { Normal parameters } \\
\text { Mean }\end{array}$ & $1.07 \mathrm{E} 4$ & $1.12 \mathrm{E} 4$ & 6109.38 \\
$\quad \mathrm{SD}$ & $2.300 \mathrm{E} 3$ & $2.258 \mathrm{E} 3$ & $3.603 \mathrm{E} 3$ \\
Most extreme differences & & & \\
$\quad$ Absolute & 0.193 & 0.180 & 0.196 \\
Positive & 0.091 & 0.109 & 0.176 \\
$\quad$ Negative & -0.193 & -0.180 & -0.196 \\
Kolmogorov-Smirnov Z & 1.335 & 1.245 & 1.359 \\
Asymp. Sig. (2-tailed) & 0.057 & 0.090 & 0.050 \\
\hline a & & &
\end{tabular}

Table 3 The average units cost for each item 2004-2008

\begin{tabular}{llllr}
\hline Items & \multicolumn{2}{l}{ Costs } & & \multicolumn{2}{l}{ Shortage cost } \\
\cline { 2 - 5 } & \multicolumn{1}{c}{$\boldsymbol{c}_{\boldsymbol{o}}$} & $\boldsymbol{c}_{\boldsymbol{h}}$ & $\boldsymbol{c}_{\boldsymbol{b}}$ & $\boldsymbol{c}_{\boldsymbol{I}}$ \\
\hline Item (I) & 2.23 & 7.898 & 0.90 & 9.350 \\
Item (II) & 2.14 & 7.567 & 1.10 & 13.254 \\
Item (III) & 9.77 & 34.542 & 3.28 & 68.460 \\
\hline
\end{tabular}

* Step 4: the procedure is to change the values of $\lambda_{i}$ in step 2 and step 3 until the smallest value of $\lambda_{i}>0$ is found such that the constraint varying shortage for the different values of $\beta$.

The numerical computation are done by using mathematica program for three items at different values of $\beta$, Table 4 shows the optimal values $Q^{*}, r^{*} \mathrm{E}(\mathrm{TC})$ and $\min \mathrm{E}(\mathrm{TC})$ at different values of $\beta$. Hence we can draw the optimal routes of $Q^{*}, r^{*}$ and $\mathrm{E}$ (TC) against $\beta$ for all three items as shown in Figs. 2, 3 and 4. It is evident that the min $\mathrm{E}(\mathrm{TC})$ is achieved at minimum value for $\beta$.

\section{Conclusion}

Upon studying the probabilistic multi item invetory model with varying mixture shortage cost under two restrictions using the Lagrange mulipliers technique, the optimal order quntity $Q^{*}$ and the optimal reorder point $r^{*}$ are introduced. Then, the minimum 


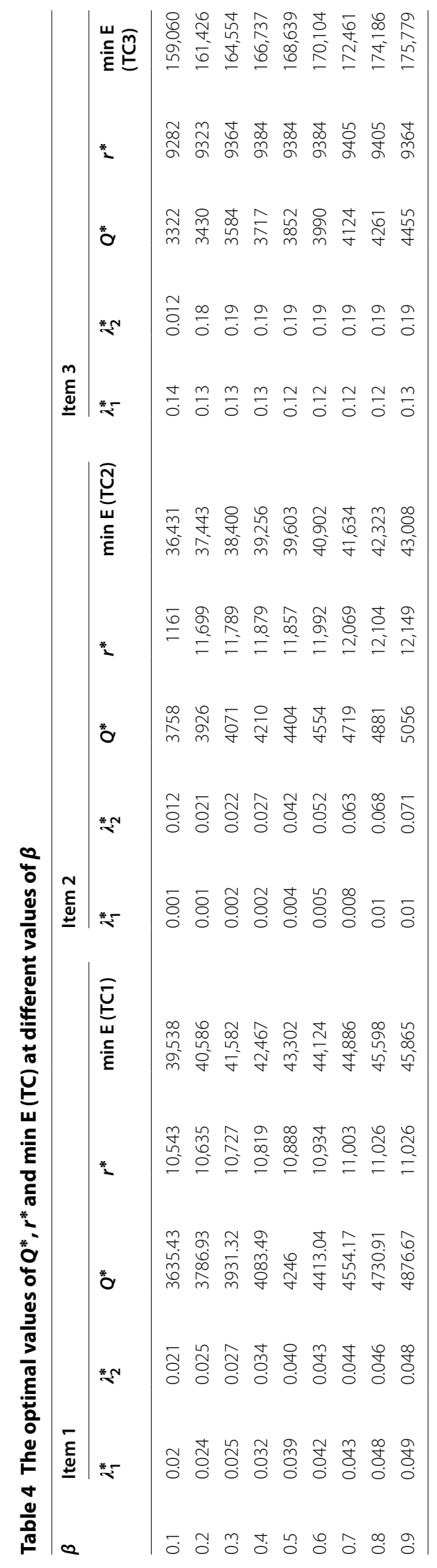




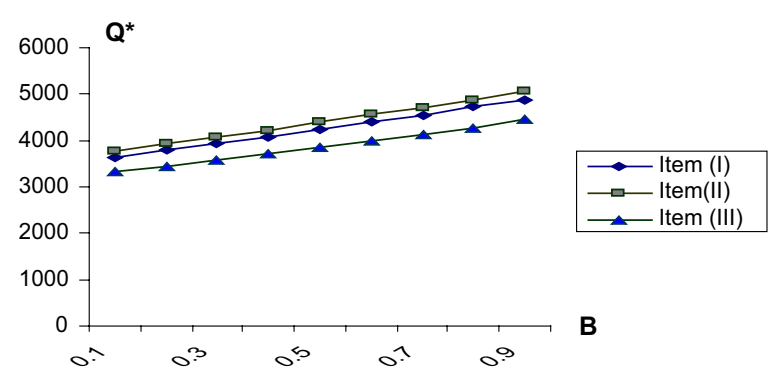

Fig. 2 The optimal values of $Q^{*}$ against $\beta$

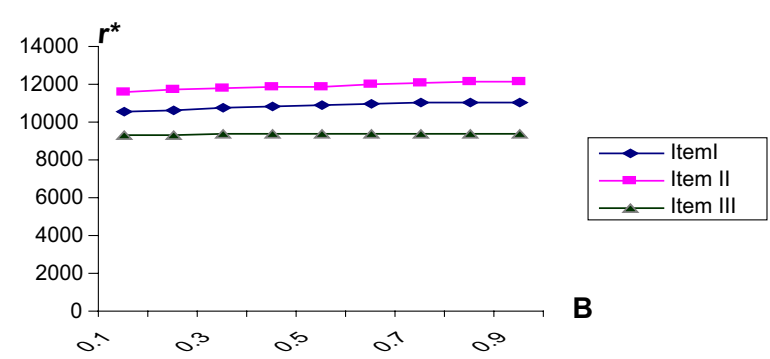

Fig. 3 The optimal values of $r^{*}$ against $\beta$

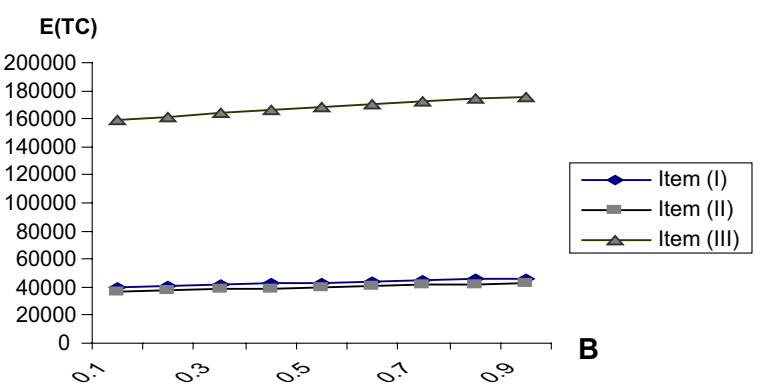

Fig. 4 The optimal values of $E(T C)$ against $\beta$

expected total cost min $\mathrm{E}(\mathrm{TC})$ for multi items are deduced. Three curves $Q^{*}, r^{*}$ and min $\mathrm{E}$ (TC) are displayed to illustate them for multi items against the different values of $\beta$. Finally, the min $\mathrm{E}(\mathrm{TC})$ is achieved at minimum value for $\beta$.

Acknowledgements

I would like to greatly appreciate the anonymous referees for their very valuable and helpful suggestions. I take this favorable chance to express my indebtedness to the Honorable Editor-in-Chief and his Editorial Board for their helpful support. I am also grateful to Department of Math \& Stat, Faculty of Science, Tanta University for infrastructural assistance to carry out the research.

Competing interests

The author declare that he have no competing interests.

\section{Appendix}

See Table 5. 
Table 5 The actual inventory quantity and demand rate, from May 2004 to April 2008

\begin{tabular}{|c|c|c|c|c|c|c|c|c|}
\hline \multirow[t]{2}{*}{ Year } & \multirow[t]{2}{*}{ No. of cycle } & \multirow[t]{2}{*}{ Month } & \multicolumn{2}{|l|}{ Item 1} & \multicolumn{2}{|l|}{ Item 2} & \multicolumn{2}{|l|}{ Item 3} \\
\hline & & & Q1 & D1 & Q2 & D2 & Q3 & D3 \\
\hline \multirow[t]{8}{*}{2004} & \multirow[t]{6}{*}{1} & May & 5800 & 6000 & 10,500 & 10,500 & 8000 & 900 \\
\hline & & June & 9000 & 8000 & 9000 & 10,000 & 5500 & 500 \\
\hline & & July & 11,800 & 12,000 & 12,000 & 12,000 & 8000 & 900 \\
\hline & & Aug & 11,800 & 12,000 & 12,000 & 12,500 & 6000 & 500 \\
\hline & & Sept. & 8000 & 8500 & 10,000 & 9000 & 4000 & 400 \\
\hline & & Oct. & 7200 & 7000 & 7500 & 7000 & 3000 & 400 \\
\hline & \multirow[t]{2}{*}{2} & Nov. & 10,000 & 10,000 & 10,000 & 10,500 & 5500 & 500 \\
\hline & & Dec. & 11,000 & 12,000 & 9000 & 9000 & 5500 & 500 \\
\hline \multirow[t]{12}{*}{2005} & & Jan. & 12,800 & 12,800 & 11,000 & 11,000 & 5000 & 550 \\
\hline & & Feb. & 11,000 & 10,000 & 7500 & 7500 & 4000 & 500 \\
\hline & & March & 6000 & 6500 & 12,500 & 12,500 & 5000 & 500 \\
\hline & & April & 9500 & 8500 & 13,000 & 12,500 & 7000 & 600 \\
\hline & 3 & May & 12,000 & 12,000 & 11,000 & 12,000 & 9500 & 10,000 \\
\hline & & June & 12,000 & 12,500 & 10,000 & 9000 & 6500 & 6000 \\
\hline & & July & 8500 & 9000 & 12,500 & 12,800 & 9000 & 10,000 \\
\hline & & Aug. & 7000 & 7500 & 17,000 & 16,000 & 7000 & 6000 \\
\hline & & Sept. & 11,000 & 12,000 & 9000 & 10,000 & 5000 & 5000 \\
\hline & & Oct. & 13,400 & 11,000 & 7800 & 8000 & 4000 & 5000 \\
\hline & 4 & Nov. & 12,850 & 13,500 & 12,500 & 12,000 & 6500 & 6000 \\
\hline & & Dec. & 12,830 & 13,000 & 11,000 & 12,000 & 6500 & \\
\hline \multirow[t]{24}{*}{2006} & & Jan. & 12,850 & 12,500 & 11,850 & 10,500 & 7000 & 7500 \\
\hline & & Feb. & 12,830 & 11,850 & 6830 & 8000 & 6000 & 7000 \\
\hline & & March & 12,820 & 12,000 & 11,820 & 12,500 & 7000 & 7000 \\
\hline & & April & 10,730 & 11,030 & 12,730 & 12,230 & 9000 & 8000 \\
\hline & 5 & May & 6500 & 7000 & 11,500 & 12,000 & 10,000 & 11,000 \\
\hline & & June & 9800 & 8500 & 10,000 & 9500 & 7500 & 7000 \\
\hline & & July & 12,500 & 13,000 & 12,800 & 12,950 & 10,000 & 11,000 \\
\hline & & Aug. & 12,200 & 13,000 & 17,000 & 16,000 & 8500 & 7000 \\
\hline & & Sept. & 9000 & 8600 & 9000 & 9500 & 6000 & 6000 \\
\hline & & Oct. & 7000 & 7300 & 8500 & 8750 & 5000 & 6000 \\
\hline & 6 & Nov. & 10,000 & 12,000 & 13,000 & 12,000 & 7500 & 7000 \\
\hline & & Dec. & 12,000 & 10,500 & 11,500 & 12,500 & 7500 & 7000 \\
\hline & & Jan. & 13,000 & 14,000 & 12,000 & 11,000 & 8000 & 8500 \\
\hline & & Feb. & 13,000 & 13,000 & 7000 & 8000 & 7000 & 8000 \\
\hline & & March & 13,000 & 12,000 & 12,000 & 13,000 & 8000 & 8000 \\
\hline & & April & 11,000 & 10,000 & 13,000 & 13,000 & 10,000 & 9000 \\
\hline & & May & 7000 & 7000 & 12,000 & 13,000 & 11,500 & 12,000 \\
\hline & & June & 10,000 & 11,000 & 10,000 & 9000 & 8500 & 8000 \\
\hline & & July & 13,000 & 13,000 & 13,000 & 14,000 & 11,000 & 12,000 \\
\hline & & Aug. & 12,000 & 13,000 & 17,000 & 16,000 & 9000 & 8000 \\
\hline & & Sept. & 9000 & 9000 & 11,000 & 9000 & 7000 & 7000 \\
\hline & & Oct. & 10,000 & 8000 & 8000 & 9000 & 7000 & 7000 \\
\hline & 8 & Nov. & 10,000 & 12,000 & 13,000 & 12,000 & 8500 & 8000 \\
\hline & & Dec. & 12,000 & 10,000 & 11,500 & 12,000 & 8500 & 8000 \\
\hline \multirow[t]{4}{*}{2008} & & Jan. & 14,000 & 14,500 & 12,500 & 12,000 & 9000 & 9500 \\
\hline & & Feb. & 13,000 & 13,200 & 8000 & 7500 & 8000 & 9000 \\
\hline & & March & 13,000 & 13,000 & 13,000 & 13,000 & 9000 & 9000 \\
\hline & & April & 11,000 & 10,000 & 14,000 & 14,000 & 11,000 & 10,000 \\
\hline
\end{tabular}


Received: 7 December 2015 Accepted: 29 July 2016

Published online: 16 August 2016

\section{References}

Abou-El-Ata MO, Kotb KAM (1996) Multi-item EOQ inventory model with varying holding cost under two restrictions: a geometric programming approach. Prod Plan Control 8(6):608-611

Abou-El-Ata MO, Fergany HA, El-wakeel MF (2003) Probabilistic multi-item inventory model with varying order cost under two restrictions: a geometric programming approach. Int J Prod Econ 83:223-231

Fabrycky WJ, Banks J (1965) Procurement and inventory theory. Volume III-the multi-item, multi source concept. Oklahoma State University Engineering Research Bulletin, no. 146

Fergany HA, El-Saadani ME (2005) Constrained probabilistic inventory model with continuous distributions and varying holding cost. Int J Appl Math 17(1):53-67

Fergany HA, El-Saadani ME (2006) Constrained probabilistic lost sales inventory system normal distributions and varying order cost. J Math Stat 2(1):363-366

Fergany HA, El-Hefnawy NA, Hollah OM (2014) Probabilistic periodic $<$ Qm,N $>$ inventory model using lagrange technique and fuzzy adaptive particle swarm optimization. J Math Stat 10(3):368-383. ISSN:1549-3644@Science Publications

Hadley G, Whiten TM (1963) Analysis of inventory systems. Prentice Hall Inc, Englewood Cliffs

Montgomery DC, Bazaraa MS, Keswani AK (1973) Inventory models with a mixture of backorders and lost sales. Naval Res Logist Q 20:255-263

Ouyang LY, Yeh NC, Wu KS (1996) Mixture inventory model with backorders and lost sales for variable lead time. J Oper Res Soc 47:829-832

Park KS (1982) Inventory model with partial backorders. Int J Syst Sci 13:1313-1317

Zipkin PH (2000) Foundations of inventory management. McGraw-Hill Book Co., Inc., New York

\section{Submit your manuscript to a SpringerOpen ${ }^{\circ}$ journal and benefit from:}

- Convenient online submission

\section{- Rigorous peer review}

- Immediate publication on acceptance

- Open access: articles freely available online

- High visibility within the field

- Retaining the copyright to your article 